\title{
CORPOS EM BUSCA DO BELO: AS MULHERES NEGRAS E A BELEZA NA EUGENIA DA ERA VARGAS
}

BODIES IN SEARCH OF THE BEAUTY: BLACK WOMEN AND BEAUTY IN THE EUGENIA OF THE VARGAS ERA

\section{Joyce Gonçalves Restier da Costa Souza}

Mestra em Ciências Sociais pelo Programa de Pós-graduação em Ciências Sociais da Pontifícia Universidade Católica do Rio de Janeiro (PUC-Rio), bolsista CAPES, mestra em Relações Étnico-raciais pelo Programa de Pós-graduação em Relações Étnico-raciais do Centro Federal de Educação Tecnológica Celso Suckow da Fonseca (CEFET-RJ). 


\section{RESUMO}

Corpos em busca do belo. Os corpos negros? Por que em busca, nem sempre foram belos? A beleza difundida pelos discursos políticos e pela publicidade na Era Vargas enaltecia a estética de mulheres adultas, jovens, brancas e de classe média. Nesse contexto, onde estaria a beleza da população negra, o que seria a beleza negra? Seguindo o pensamento de Nilma Lino Gomes "a beleza negra seria uma ideologia racial gestada no interior da comunidade negra na tentativa de devolver o status de humanidade roubado desde os tempos da escravidão" (GOMES, 2008, p. 263), assim, a constituição social dos corpos negros estaria impregnada do dissenso entre a herança africana evidente na corporeidade e o discurso político do branqueamento.

PALAVRAS-CHAVE: mulheres negras; eugenia; movimento negro; beleza negra.

\section{ABSTRACT}

Bodies in search of the beautiful. Black bodies? Why in search, weren't they always beautiful? The beauty spread by political speeches and publicity in the Vargas Era praised the aesthetics of adult, young, white and middle-class women. In this context, where would the beauty of the black population be, what would black beauty be? Following the thought of Nilma Lino Gomes "Black Beauty would be a racial ideology created within the black community in an attempt to return the status of humanity stolen since the times of slavery" (GOMES, 2008, p. 263), thus, the social constitution of black bodies would be impregnated with the dissent between the African heritage evident in corporeality and the political discourse of money laundering.

KEYWORDS: black women; eugenics; black movement; black beauty. 


\section{Corpos em busca do belo. Corpos negros? Por que em busca, nem sempre foram belos?}

Nosso debate se debruça sobre os conceitos de embelezamento engendrados no início do século XX por meio da política de estado projetada com fins de branqueamento da população nacional, elegendo a miscigenação como traço marcante do povo brasileiro e, ao mesmo tempo, um entrave para o progresso da nação. Muitos intelectuais nesse período observaram e ratificaram as teses sobre a mestiçagem apontando-a como a causa do atraso brasileiro, bem como realizaram prognósticos sobre o desaparecimento dos caracteres negros do sangue brasileiro, a partir da intensa miscigenação, projetada junto com o incentivo à imigração europeia.

Atuando e reforçando essas medidas estava a eugenia defendida por um de seus principais intelectuais, Renato Kehl, ${ }^{1}$ como "uma ciência e uma arte" (FLORES, 2007, p. 39) que tinha por objetivo "modernizar o país e apagar os símbolos da degeneração" (SANTOS, 2008, p. 20), ou seja, para modernizar o país seria necessário eliminar toda e qualquer referência que trouxesse a negritude e a africanidade em seus significados.

A eugenia de Francis Galton surgiu da premissa da naturalização e da individualização das causas dos males sociais. Foram realizadas pesquisas sobre hereditariedade e genética, relacionando as hierarquias de classe com as diferentes raças humanas, diferenciando-as por meio de novas disciplinas científicas como a frenologia e a antropologia criminal (SCHWARCZ, 1993). Cada uma dessas disciplinas, ciências na época, atestavam por meio de suas análises a superioridade da raça branca, determinando assim uma hierarquização sobre os tipos fenotípicos dos seres humanos.

Os fenótipos tornaram-se, então, os sinais diacríticos que determinaram as diferenças sociais e sexuais no século XIX. Por meio de suas características físicas, seres humanos foram classificados e hierarquizados em raças humanas. A raça branca foi relacionada à perfeição, admirada como referencial positivo, aquele que correspondia ao indivíduo "civilizado": masculino, branco e europeu. Já os indivíduos pertencentes à raça negra (bem como indígenas e orientais) foram classificados como selvagens, incapazes de civilizar-se e até mesmo animalizados, pois suas características físicas foram equiparadas e induzidas à semelhança com animais. Dessa maneira, a estética e a beleza, como atuavam fundamentadas nos fenótipos, tornaram-se preponderantes na diferenciação e na classificação também entre culturas e civilizações. As raças humanas estavam diretamente relacionadas ao aspecto físico, ao comportamento social e à capacidade de civilizar-se, ou seja, à capacidade

\footnotetext{
${ }^{1}$ Médico eugenista, um dos principais representantes do campo eugênico no país. "Desde as primeiras décadas do século XX até a data de sua morte (1974), ele esteve envolvido com o debate sobre a pertinência da eugenia como o remédio para os vários males da sociedade brasileira" (SANTOS, 2008, p. 11).
} 
de adquirir comportamentos e condutas característicos do povo europeu. Para os teóricos respaldados pela eugenia, quanto mais próximo ao africano, menor a possibilidade desse tipo de sociabilidade.

O cânone estético sugerido pelos cientistas eugênicos é aquele semelhante em cultura física aos gregos na Antiguidade clássica, pois estes construíram no seu amor a beleza plástica, uma harmonia em suas formas que serviram aos eugenistas como modelo de normalidade (FLORES, 2007). Em relação à construção de um conceito de normalidade, apontamos a utilização de corpos negros para a análise comparativa desde o século XIX. Segundo Amanda Braga (2015), o corpo de uma mulher negra foi utilizado como parâmetro referencial para a construção de discursos sobre os corpos de negras e negros, essa mulher era Saartjie Baartman² (Vênus Hotentote), africana com características corporais únicas de sua etnia hotentote.

Seu corpo foi utilizado, tanto em vida como depois de sua morte, como modelo de imperfeição e inferioridade em relação ao corpo masculino branco e posteriormente ao feminino, que era representado pela Vênus de Milo (Figura I). Situada como uma "mulher africana típica, nesse palco a hotentote será a prova final do parentesco entre o animal, o monstro e o selvagem" (BRAGA, 2015, p. 4I), criando assim um imaginário que se tornará discurso em relação ao seu corpo e o de seus semelhantes. A partir dessas comparações, ainda segundo a autora, a diferença racial alimentaria um abismo entre europeus e africanos. Assim:

Durante todo o século XIX, assistiu-se à exibição de africanos em feiras, teatros, circos e exposições. Ao lado de animais, ao mesmo tempo em que se expunham para deleite dos europeus, foram observados e estudados como elementos capazes de confirmar teorias médicas eugenistas, que versavam acerca da superioridade da raça branca. Dentre os grupos de raça inferior, a mulher em particular, figurava como ainda mais inferior, uma vez que limitada sua capacidade racional em detrimento de seu instinto. (BRAGA, 2015, p. 4I)

\footnotetext{
${ }^{2}$ Saartjie Baartman, nascida em 1789, na África do Sul, segundo Braga (2015, p. 39), pertencia ao povo Khoisan, considerada a mais antiga etnia humana estabelecida da parte meridional da África. Foi adotada aos 10 anos por uma família de agricultores holandeses na condição de serva, e por não saberem o nome de batismo foi chamada de Saartjie (pequena Sarah), herdando o sobrenome da família adotiva Baartman. Sobre a história de Saartjie, ver DAMASCENO, J. O corpo do outro. Construções raciais e imagens de controle do corpo feminino negro: $\mathrm{O}$ caso da Vênus Hotentote. In: FAZENDO GÊNERO, 8., 2008, Florianópolis. Anais... Florianópolis: UFSC, 2008. Disponível em: <http://www.fazendogenero.ufsc.br/8/st69.html>. Acesso em: 9 set. 2011.
} 


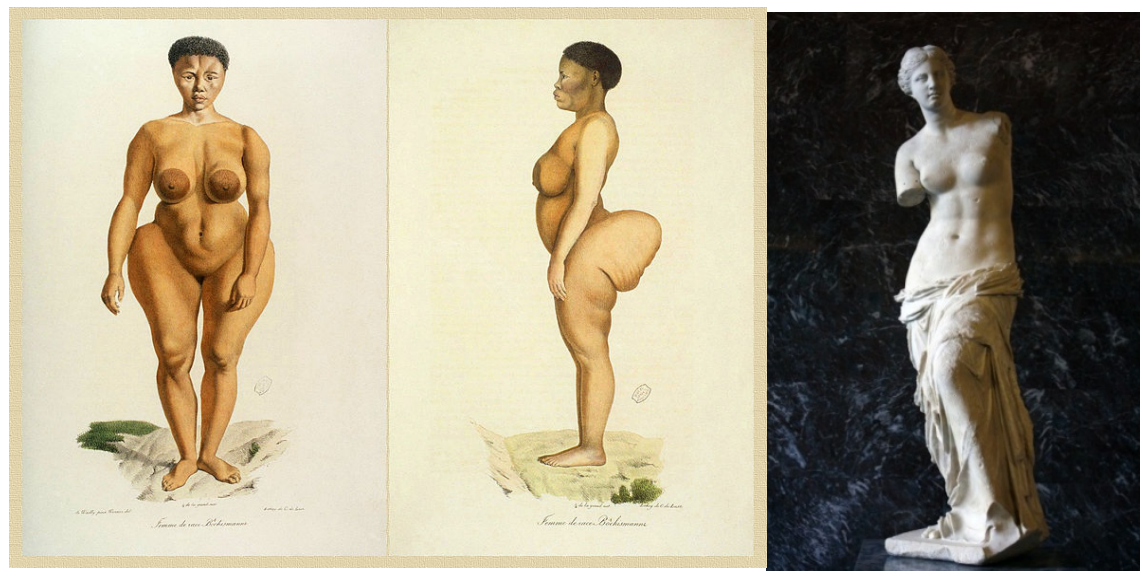

Fonte: Vênus Hotentote: Braga (2015, p. 131); Vênus de Milo: VÊNUS DE MILO. In: WIKIPÉDIA, a enciclopédia livre. Flórida: Wikimedia Foundation, 2020. Disponível em: <https://pt.wikipedia.org/w/index.php?title=V\%C3\%AAnus_de_Milo\&oldid=58294147>. Acesso em: 31 mai. 2020 .

Assim, desde o século XIX o imaginário social europeu seguiu povoado pelas representações pejorativas sobre mulheres e homens negros. De acordo com Janaína Damasceno (2007) apoiada em Wiss (1994), "foi a partir das exibições públicas do século XIX que os europeus começaram a perceber a diferença e notaram, ao escrutinizar Sarah, que esta poderia assumir um caráter racializado e sexualizado através de seu corpo", percepção que, segundo a autora, legitimaria a identidade civilizada do homem europeu.

Ao considerar as importações dos conhecimentos científicos que ocorriam nesse período, pode-se afirmar que essas representações assumiram um sentido de verdade no Brasil, pois de acordo com Foucault (I984, p. IOI):

Em qualquer sociedade, existem relações de poder múltiplas que atravessam, caracterizam e constituem o corpo social e que estas relações de poder não podem se dissociar, se estabelecer nem funcionar sem uma produção, uma acumulação, uma circulação, um funcionamento do discurso [...] estamos submetidos à verdade também no sentido em que ela é lei e produz discurso verdadeiro que decide, transmite e reproduz, [...] somos destinados a um certo modo de viver ou morrer em função dos discursos verdadeiros que trazem consigo efeitos específicos de poder.

No Brasil, os efeitos desse poder médico-científico se encontravam principalmente em um complexo de práticas discursivas que relacionavam as características físicas, então raciais, ao comportamento, às atitudes e à capacidade cognitiva, sempre de maneira inferiorizada e estereotipada, aos sujeitos negros. Isso criava formas de viver que lhe 
usurpavam a humanidade, gerando uma onda de medo e rejeição aos milhares de africanos escravizados em terras brasileiras.

No Brasil, a população negra padeceu com a importação desses conceitos, uma vez que balizavam os discursos sobre a imagem e o comportamento dos negros. Como bem exprime Amanda Braga (2015, p. 49), "as marcas de uma Vênus Noire à brasileira estão espalhadas pelos arquivos do período escravocrata: pinturas, depoimentos de viajantes, anúncios de jornais, relatos históricos". Pode-se constatar assim que o corpo da mulher negra carregado de discursos negativos, "considerado anormal e desviante ao masculino europeu", foi um dos instrumentos pelo qual o discurso médico construiu um conceito de negritude.

Nele [discurso médico], se articulavam categorias de raça e sexo que universalizadas acabaram por criar o estereótipo de hipersexualidade da mulher negra que impera até hoje e que foi estendida aos homens negros em geral. [...] O corpo de Saartjie tornou-se "ícone da diferença sexual, ela era a alteridade personificada". (GILMAN, 1985 apud DAMASCENO, 2007, grifo nosso)

Sobre os referidos discursos acerca dos corpos de mulheres negras, tanto no século XIX quanto no século XX, observa-se a perpetuação de estereótipos construídos a partir da imagem de Saartjie. A hipersexualização, a ausência de beleza e a atribuição de juízo moral aos comportamentos sociais são exemplos que influenciaram a interpretação sobre esses corpos. Essa interpretação teve nos estereótipos disseminados pelo discurso europeu a base de sua estruturação restando aos sujeitos os quais esse discurso difamava ressignificar seus signos a fim de constituir uma linguagem contra-hegemônica que representasse sua identidade. E foi desse modo, ressignificando seus signos, que as mulheres negras brasileiras reelaboraram sua concepção de beleza em meio à conjuntura que realçava a beleza e o comportamento social de brancos de classes abastadas como modelo de representação do nacional.

\section{A beleza na Era Vargas: um povo saudável e belo para o progresso da nação}

Durante a Era Vargas (1930-1945), de acordo com Nancy Stepan (2004, p. 374), a aproximação entre a eugenia e o regime de Estado se deu pela conformidade de objetivos. Afinal, por meio da ciência seria possível o desencadear da busca por uma imagem do povo brasileiro, e com isso reorganizar a realidade social brasileira para o progresso desejado. $\mathrm{O}$ empenho por uma referência imagética para a população brasileira estava alicerçado pelo discurso médico eugenista que atrelava corpo, saúde e beleza como sinônimos de progresso e inclusão nas nações modernas. 
A atuação da eugenia oferecia ao país a oportunidade de apagar os rastros da herança negra, de geração em geração, proporcionando um avanço na capacidade brasileira de alcançar o progresso, além disso poderia modificar o tipo físico, psíquico e moral do povo atribuindo a este uma representação que fizesse jus ao futuro moderno e civilizado. Esta era a preocupação dos médicos, que a educação e a medicina fossem capazes de modificar a realidade social brasileira. Que o homem nacional fosse uma raça regenerada e aprimorada por meio do conjunto de ações impostas aos corpos da população, seja educando, curando, controlando ou transformando. (SILVA, 2015, p. 52)

Essa modernização se daria, como é possível observar, com a disciplinarização dos comportamentos sociais dos indivíduos por meio da educação e da medicina. Desse modo, o poder do Estado se estabeleceria no corpo da população, com métodos científicos, na tentativa de corporificar uma nacionalidade ainda inexistente. O homem nacional, então, seria o resultado de um investimento maciço nos corpos negros e mestiços a fim de que branqueassem se não física ao menos culturalmente suas condutas, materializando o poder do Estado em seus corpos. Segundo Foucault (1984) é justamente por meio dessa materialização que se constitui o corpo social. No Brasil, esse corpo social precisava ser saudável, produtivo, branco e civilizado.

Por meio do melhoramento da raça, tendo como base o ideal do branqueamento, seriam alcançados o progresso e a ordem, princípios do positivismo, que manteriam os privilégios e as funções de classe. Com apenas três décadas de abolição da escravidão negra no Brasil e um alto investimento no branqueamento da população, as questões raciais estavam no cerne da aceitação da ciência eugênica no país.

Seguindo a ideologia eugenista, quanto mais belo o povo maior seu aprimoramento moral e espiritual e, consequentemente, mais moderna a nação. Para concretizar esse objetivo, as mulheres foram encarregadas - não só pelos cuidados com seu corpo e pela preservação de sua beleza como também pela difusão no seio familiar - das normas higiênicas e sociais. Segundo Silva e Goellner (2008, p. 254), Renato Kehl "elege em sua obra a beleza feminina como dever de toda mulher, responsabilizando-as por valorizar seus dotes físicos e disfarçar as imperfeições". Na eugenia, todos os atributos físicos femininos precisavam ser cuidados e tinham um significado na obtenção do ideal de mulher eugênica.

A mulher eugênica brasileira deveria "cultivar em seu corpo a beleza honesta por meio de estímulos fisiológicos dos exercícios ginásticos - sua beleza deve ser natural e higiênica. Saúde, honestidade, robustez e formosura são predicados que se tornaram centrais" (SILVA; GOELLNER, 2008, p. 257). Assim, a disseminação da eugenia esteve nos setores que atingiriam o maior número de pessoas, difundindo seu discurso e tornando-se um ideal a ser perseguido. À 
vista disso, sabonetes, medicamentos e cremes para pele eram produtos anunciados mantendo a promessa de corpos limpos, belos e saudáveis:

Em anúncios de pós e cremes para o rosto, os brancos associavam-se às condutas saudáveis e a um modelo único de beleza: "Uma pela branca, delicada e fina dentro da qual se vê circular a vida, deve ser o ideal de toda mulher". Peles encardidas, conforme anunciava a propaganda, precisavam ser regeneradas. (SANT'ANNA, 2OI4, p. 76)

Os discursos desses anúncios tendiam à afirmação de uma estética que valorizava a pele alva e os cabelos lisos como representação da beleza feminina, e a condenação dos tons de pele mais escuros, associando-os à sujeira e ao encardido. Sugeriam, ainda, que a brancura da pele se relacionava ao status social do indivíduo. Segundo Sant'Anna (2014, p. 64) "a pele alva não se limitava à brancura, pois abarcava também a ausência de manchas e cicatrizes. Moças alvinhas, conforme se dizia, simbolizavam saúde, status, riqueza e limpeza".

\section{Figura 2. Propaganda do Leite de Colônia.}

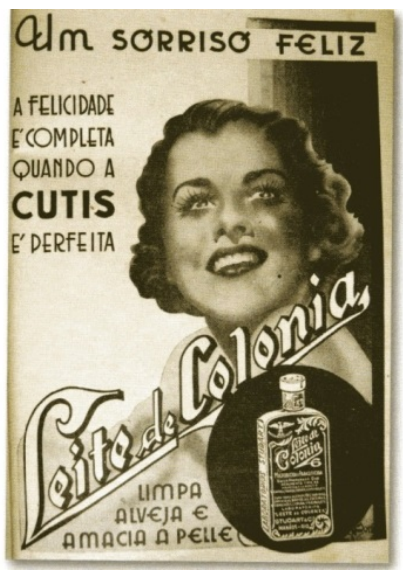

Fonte: Revista Educação Physica, n. 6, 1936.

A imagem vinculada na propaganda do produto Leite de Colônia (Figura 2), em I936, é uma dentre inúmeras relacionadas à higiene pessoal, como sabonetes, cremes para a pele e até medicamentos, que ilustravam um perfil feminino, o potencial consumidor do produto. Ademais sugeriam implicitamente a imagem final daquelas que se dispusessem a utilizá-lo. Com o slogan: "Limpa e alveja a pele", percebe-se o quão comum deveria ser a proposição de embranquecimento da pele, seja por meio da limpeza ou dos artigos de maquiagem, tendendo a fixar na memória e no discurso feminino a associação entre limpeza, brancura e beleza. Dessa maneira, a eugenia e a política da beleza, a partir de olhares masculinos, agiam como possíveis alicerces na constituição de uma identidade feminina, atuando na determinação de padrões de beleza, bem como nos comportamentos admissíveis para o gênero. 


\section{Mulheres negras e a beleza: ressignificando signos, afirmando a beleza negra}

O valor social dos aportes identitários para a mulher negra, como o corpo e o cabelo crespo, seriam tanto objetos de identificação e resgate da ancestralidade africana quanto objetos de rejeição, passando por reinterpretações ancoradas no branqueamento e na pretensão de inserção social. A constituição social dos corpos de mulheres negras estaria, então, impregnada do dissenso entre a herança africana evidente na corporeidade, a contínua resistência e o discurso político do branqueamento.

Essas mulheres buscavam seus rendimentos em atividades desenvolvidas na rua, atuando como vendedoras, lavadeiras, floristas, doceiras, operárias e empregadas domésticas. Profissões que exigiam empenho, certo trabalho físico e disponibilidade de seus corpos nas vias públicas onde ocorreriam as vendas, contrariando o que as mulheres não negras tinham como padrão de comportamento. Um exemplo eram as jovens de famílias abastadas que iniciavam sua carreira como professoras, médicas, advogadas, biólogas, pintoras, pianistas, estando alocadas em profissões que tinham certo status social e onde o acesso ao público era limitado.

Os comportamentos sociais exigidos pelas profissões e pela classe social seriam os códigos que, de alguma maneira, designariam o lugar e a função social à qual pertenciam, afinal, nesse contexto, a cor da pele e os modos de ser, estar e agir representavam as diferenças sociais e raciais da época.

As mulheres negras encontravam-se inseridas em um contexto social no qual os códigos sociais possivelmente eram outros, tanto que, para Rago (2013, p. 589), as profissões exercidas por elas "eram estigmatizadas e associadas à imagem de perdição moral, de degradação e de prostituição", devido a uma associação entre o trabalho braçal e o serviço realizado pelos escravizados, relacionando o tipo de serviço executado a uma "incapacidade pessoal de desenvolver qualquer habilidade intelectual ou artística e à degeneração moral".

De certo modo, as ocupações sociais desempenhadas pelas mulheres pobres e negras as enquadravam em outros estereótipos diretamente relacionados à beleza e à saúde. Estereótipos que estimulavam um tipo de percepção que as representava em estado de subalternização e inferiorização de sua estética. A imagem atribuída às mulheres pobres estaria vinculada ao desleixo e a estrutura sociocultural, incentivando a produção de uma imagem pejorativa, retratando-as como maltrapilhas, sujas e portadoras de doenças. A dificuldade na obtenção de renda, o baixo poder de consumo em razão do sustento da casa, seu comportamento em público muitas vezes arredio e autônomo, e o possível quadro de analfabetismo poderiam ser fatores que afastariam essas mulheres dos padrões estéticos e dos cuidados com o corpo divulgados pela publicidade e exercidos por mulheres da "elite". 
Ainda assim, a aparência continuava preponderante na determinação da ocupação social das mulheres negras. Era sob a cortina da "boa aparência" que a discriminação racial se fazia presente nas escolhas de candidatas no mercado de trabalho formal. O eufemismo da "boa aparência" dissimulava a descrição racial, mas deixava subentendido a intenção da escolha por candidatas mais claras. Cabia, então, às candidatas negras perceber que "as características fenotípicas eram vitais na interpretação de regras culturais e com elas se aprenderia a interpretar a 'boa aparência' e os modos possíveis de se haver com ela para conseguir manter um lugar no trabalho" (DAMASCENO, 20IO, p. IO6).

O ponto em que essas mulheres precisariam lidar com a interpretação da "boa aparência" seria aquele para o qual se direcionaria a modificação de sua estética e de sua cultura, adequando-se ao perfil hegemônico, porém de maneira alguma poderemos deixar de lado o fato de que, para cada imposição, houve uma resistência, pois, segundo Deleuze (1976, p. 2I), "nenhuma força renuncia ao seu próprio poder. As forças inferiores exercem suas forças assegurando os mecanismos e as finalidades, preenchendo as condições de vida e as funções, as tarefas de conservação, de adaptação e de utilidade". Com isso podemos perceber uma dinâmica entre o poder e a resistência. A eugenia agindo nas imposições de padrões e a resistência da comunidade negra apostando na transformação, na modificação ou na adaptação do próprio corpo em busca de um meio termo que conseguisse abranger a possibilidade de integração social e a manutenção da identidade racial.

Essa dinâmica permitiu que os corpos negros e seus aportes culturais sobrevivessem às imposições do poder, dialogando e recriando novos aportes e símbolos que caracterizariam e marcariam a corporeidade negra no decorrer dos séculos.

Assim, mulheres negras na sociedade brasileira, com sua ancestralidade e sua percepção de mundo sufocadas têm, nas negociações e reelaborações, suas potenciais estratégias de sobrevivência. Sua beleza poderia, então, estar ancorada em um conjunto de expressões corporais e suportes simbólicos, aglutinados no comportamento social, bem como no formato dos fios de cabelo, na tonalidade da pele e nos traços fisionômicos, que as caracterizaram e as classificaram na hierarquização de uma sociedade racializada.

Nesse cenário a comunidade negra desenvolveu a construção de uma concepção de beleza negra que pudesse estar em paralelo com a beleza hegemônica, pois "a categoria de beleza negra era cívica, tinha um objetivo explícito que lhe era caro: superar as marcas de um passado repleto de dores e subtrações sem, contudo, apagar as glórias, a força e a inventividade de escravas e descendentes" (XAVIER, 20I3, p. 430). Do início até a metade do século $\mathrm{XX}$, a imprensa negra paulista ${ }^{3}$ se tornaria um marco na luta antirracista, na tentativa

\footnotetext{
${ }^{3}$ A resistência aos mecanismos racistas de opressão mobilizou a organização da comunidade negra em associações e clubes. Começaram com as irmandades religiosas como um meio para professassem sua fé; logo vieram as associações e os clubes
} 
de visibilizar e valorizar a população negra em suas vivências, seus comportamentos e suas adequações à sociedade racista por meio de suas mulheres.

Haveria um investimento em escolas, salões de beleza, assistência médica e banco de empregos. A Frente Negra Brasileira (FNB), protagonista nesse investimento, fundada em I93I, teve como objetivo elevar a imagem dos negros brasileiros por meio de sua afirmação racial:

[...] criando uma série de símbolos diacríticos (carteira de identidade contendo foto e dados pessoais do filiado; uniforme para alguns departamentos; bandeira; hino), a fim de garantir visibilidade de suas ações, gerar uma identidade específica aos seus associados e, ao mesmo tempo, adquirir credibilidade no seio da população negra e na sociedade em geral.(DOMINGUES, 2008, p.63)

As regras de sociabilidade eram aquelas que, regida pela classe dominante, por meio da conjunção de preceitos eugênicos e higiênicos, estabelecia comportamentos sociais que pudessem representá-los como classe e grupo social. Estes iriam desde o comportamento em locais públicos e vestimentas, a níveis de instrução. De tal modo que "os costumes, a religião, e 'as usanças' da comunidade negra paulistana também deveriam acompanhar a marcha da civilização" (LOPES, 2002, p. 34), logo seria necessário estabelecer padrões de comportamento para que pudessem dissimular os possíveis motivos à ridicularização de seus associados.

Nessa perspectiva, observa-se um insistente apelo pela "boa apresentação", a qual estaria relacionada não somente à aparência física, como os conceitos de beleza à época, mas também ao caráter, à moral, ao trabalho para os homens e ao recato para as mulheres. Era estimulado que tivessem empenho na instrução e no vestir-se, e ainda os cuidados com os vícios (principalmente o alcoolismo) e moderação nas atividades de lazer (como os bailes dançantes), o que os diferenciaria da população de rua, afastando-os dos estereótipos.

Cabelo e pele foram atributos tratados pelos jornais e também foco de campanhas publicitárias. Para o embelezamento dos cabelos foram produzidos diversos anúncios sobre salões especializados, como Salão Brasil, Instituto Dulce e ainda o Salão Frente-Negrino. Como era negada a presença de negros em alguns estabelecimentos, inclusive em salões de embelezamento, o empreendimento voltado para o público negro, além do retorno financeiro, emancipava e tentava formar um critério de boa aparência dentro da comunidade

recreativos para que esses sujeitos tivessem seus espaços de lazer preservados dos discursos racistas e da exclusão. Com o avanço das associações recreativas vieram os jornais, gerando assim a imprensa negra que, em São Paulo, esteve mais evidente pelo fato de "o projeto nacional de embranquecer a não ser por meio da imigração mostrou-se mais eficaz e os efeitos excludentes sobre a população negra foram mais notórios" (ALBERTO, 2014, p. 382), quando no Rio de Janeiro partia a visão emergente de cultura nacional onde a negritude e a africanidade atuavam como elementos essenciais à identidade brasileira mista. 
negra. $\mathrm{O}$ corte à moda francesa e os cabelos lisos eram símbolos de modernidade e beleza à época também na comunidade negra. Anúncios de "alisadeiras" eram comuns, bem como o de produtos revolucionários no tratamento dos cabelos crespos.

Figura 3. Chapinha, pente quente, marcel grande e marcel pequeno (à esquerda); cabelisador (à direita).
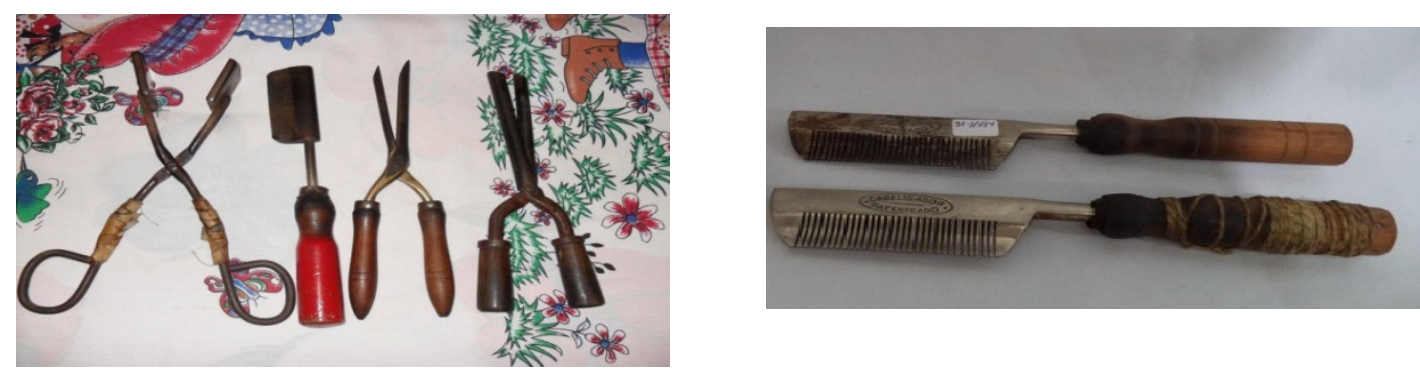

Fonte: Silva (2015, p. 123).

Assim, "os cuidados com o corpo era um trabalho a ser realizado no dia-a-dia [sic], principalmente depois de meados dos anos 1930. A beleza negra, além de ser um dom dado por Deus, tornava-se o resultado de um trabalho constante" (LOPES, 2002, p. 6I). Para o tratamento da pele, havia sim um esforço publicitário nas propagandas de pós de arroz e maquiagens que valorizavam a pele branca. Aceitando a corrente ideológica, na qual a pele bronzeada em demasia era considerada encardida e suja, havia uma preocupação dos pensadores negros em solicitar, junto com os cuidados ligados à higiene pessoal e vestuário, o asseio com os dentes, com os odores, e uma atenção especial à pele. De maneira que, com esses procedimentos, seus associados se afastassem dos estereótipos, indicando não o embranquecimento, mas a uniformidade da pele, a manutenção dos dentes e a utilização de perfumes como os principais cuidados corporais que poderiam possibilitar a aproximação e integração na sociedade paulista.

É preciso ponderar sobre os cuidados com a pele e os cabelos realizados e incentivados pela comunidade negra. Como já dito, o objetivo era afastar os corpos negros dos estereótipos associados aos corpos escravizados, com isso qualquer característica física, vestimenta e maneiras de ordenar os cabelos precisavam estar alinhadas ao que a sociedade exigia. Assim, Panos da Costa, tranças, cabelos curtos e crespos para mulheres; barbas não alinhadas e cabelos crespos compridos para homens eram evitados e até mesmo rechaçados. Outra questão eram os produtos disponíveis para esses cuidados. Os produtos de embelezamento e cuidados para a pele eram predominantemente voltados para mulheres brancas, já os produtos para cabelos crespos eram em sua maioria para o alisamento (XAVIER, 2OI3). Nesse sentido, o embelezamento e os cuidados com a aparência precisavam seguir as tendências da cultura mundial, tanto que havia um esforço dos 
brancos brasileiros em cultivar a brancura a fim de se assemelhar aos brancos europeus por meio da "apropriação cultural" dos modos franceses. Atitudes corporais, vestimentas, cortes de cabelo, arquitetura, idioma, entre outros aspectos da cultura francesa foram amplamente compartilhados na sociedade brasileira como modelo de civilidade.

Para a comunidade negra, então, como bem expôs Xavier (20I3), o discurso sobre a aparência trazia a beleza que se pretendia cívica, atuando como meio de integração na sociedade e relativa melhoria na condição de vida, sendo construída na tentativa de transformar visões e percepções sobre a comunidade negra, elevando a imagem de mulheres negras e, com isso, valorizando a historicidade do povo "de cor", como eram retratados, investindo em um discurso de "melhora da aparência".

O contato com todos esses discursos fez com que a população negra reelaborasse alguns de seus signos a fim de que pudessem incorporar em seus membros valores estéticos que, além de propiciar uma autoestima positiva, oportunizaria melhor entrada nos círculos sociais. Supõe-se que uma dessas reelaborações se refere justamente ao corpo. O corpo negro - ou melhor, os corpos das mulheres negras -, que em períodos anteriores recebeu uma descrição detalhada de seus atributos tratados como objeto e esvaziado de seus símbolos, a transcrição de suas marcas simbólicas (tatuagens e escarificações) como deformidades, passa a ser ocultado nas interpretações da beleza negra, sendo ressaltadas qualidades ligadas à instrução e à moral, como exemplifica Xavier (2012), quando relata que não seria a beleza física o único quesito a representar a beleza negra nos jornais da classe, "era preciso também ser honrada, recatada e bem-educada como eram as moças brancas da alta classe, reverenciadas por competições de simpatia, virtuosismo e elegância promovidas pelo periodismo brasileiro" (p. I72).

À vista disso, a partir da imagem e da beleza de suas mulheres, os jornais voltados para a comunidade negra pretendiam construir personagens que, por meio da instrução e do comportamento, pudessem representar a raça negra através de discursos e ações na sociedade. Personagens que, a partir da imagem dessas mulheres, seriam os exemplos a serem perseguidos e que na verdade ainda não retratavam a realidade social do grupo, e nesse intuito foram realizados concursos de beleza masculinos e femininos em busca de representantes para a classe que se queria formar dentro da comunidade negra.

A FNB "veiculou valores éticos, morais, culturais e ensinamentos de como o negro devia se comportar socialmente, tanto na esfera pública quanto na privada" (DOMINGUES, 2007, p. 364), construindo um padrão de comportamento que pudesse diferenciá-los dos outros "irmãos de cor" e também dos brancos. Próximo ao final da década de 1940 outra entidade social surgiu no cenário nacional, também promovendo concursos de beleza, enaltecendo a beleza e a autonomia de mulheres negras. Seria o Teatro Experimental do 
Negro (TEN). Fundado em I944, no Rio de Janeiro, "o TEN significou um ato de protesto pela ausência do negro nos palcos brasileiros" (DOMINGUES, 2008, p. 69), e não foi só isso, mas também um movimento que revelava a identidade étnica do negro brasileiro por meio da valorização de sua ascendência africana.

Isso o diferenciou da FNB e das outras associações negras paulistas que, por força da conjuntura, tiveram na dinâmica de aceitação/rejeição da ascendência africana os suportes para a estruturação da imagem do novo negro brasileiro. Essa dinâmica esteve estabelecida no decorrer da atuação dessas associações: quando promoveram concursos que exaltavam a beleza negra, investiram na constituição de um padrão de comportamento que tentava adequar o negro às normas de sociabilidade vigentes e ao mesmo tempo o colocava em confronto com os brancos.

A proposta do TEN seria na "teoria e na prática a ligação entre atuação política com a afirmação e valorização da cultura brasileira de origem africana" (NASCIMENTO, 2008, p. I2I), trazendo uma nova roupagem à luta negra e erguendo novos pilares na atuação.

Os concursos realizados pelo TEN tinham como objetivo:

[...] proporcionar às mulheres negras uma oportunidade de se projetarem socialmente, de se valorizarem através dessa demonstração pública, em grande estilo, dos seus predicados, de suas virtudes, da sua vivacidade mental, graça, elegância e, sobretudo, de sua integridade no que há de mais categorizado em matéria social. (QUILOMBO apud DOMINGUES, 2008, p. 74)

Esse objetivo era um afrontamento aos concursos de miss em voga na época. Nesses concursos apenas candidatas brancas eram selecionadas, pois seriam as futuras candidatas ao concurso de Miss Universo, o que projetaria a imagem da raça brasileira no mundo. Para os intelectuais da época, essa era a oportunidade de mostrar ao mundo e ao Brasil o que se esperava como imagem do povo brasileiro, da mulher brasileira. Assim, "o tipo escolhido não deveria ser exatamente o tipo médio brasileiro, mas o tipo ideal: a beleza da mulher brasileira branca" (FLORES, 2007, p. 29). Para Roquette-Pinto:

Se fôssemos escolher o tipo mais frequente em uma determinação científica, seria melhor não comparecer ao concurso [...], onde existe a "color line" e onde uma gota de sangue negro, que às vezes dá tão grandes atributos a alguns de nossos mais belos tipos, é desgraça definitiva. (ROQUETTE-PINTO apud FLORES, 2007, p. 30)

Segundo Braga (2015, p. I24), a empreitada pelo reconhecimento racial incomodava a classe dominante branca, "que desfilava seus padrões de brancura e se fazia cega aos bens culturais afro-brasileiros", pelo fato de confrontar a problemática racial, alertando aos 
negros envoltos pelo branqueamento e pela democracia racial "de uma forma identitária de afirmação racial, por meio da educação, da política e das artes cênicas", valorizando a cultura afro-brasileira principalmente em sua estética, representada por suas mulheres.

Desse modo, as mulheres negras que se viam repelidas dos concursos de miss e logo estavam invisibilizadas em critérios de beleza, tiveram na iniciativa do TEN, na capital do país, a possibilidade de visibilidade de seus atributos, suas qualidades como belas. Visibilizaram-se também os artistas negros, por conta de suas peças teatrais e seus eventos sociais, e ainda contribuíram para que a beleza negra pudesse ser observada não somente como identidade coletiva negra representada pelo comportamento e pela polidez de suas candidatas, mas também pelas qualidades físicas características de suas mulheres:

O TEN, com a promoção dos concursos de beleza, abriu uma via de valorização das mulheres negras calcadas em seu próprio padrão estético: uma resposta ao critério racista engendrado pelos concursos de beleza que apenas aceitavam inscrição de mulheres brancas. Era um modo de resgatar a autoestima dessas mulheres, massacradas por uma estética exclusivista e eurocêntrica de beleza.(BRAGA, 20I5, p. I24)

Os concursos realizados foram: Rainha das Mulatas, em 1947 (Figura 4); Glamour Negro Girl e Boneca de Pixe, ambos em 1948. Os concursos recebiam denominações que traziam à tona adjetivos considerados pejorativos para a comunidade negra, o que, de acordo com Braga (2015), era também um protesto discursivo sobre as denominações atribuídas às mulheres negras na tentativa de valorar esses adjetivos juntando a eles a afirmação racial de mulheres negras, belas e coroadas como rainhas.

Figura 4. Maria Aparecida Marques, Rainha das Mulatas (1948).

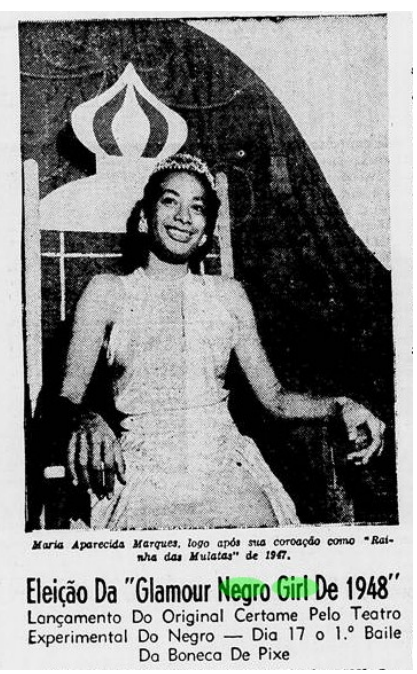

Fonte: Revista Momento Feminino, n. 24, p. 5, 1948. 
À vista disso, todas as formações discursivas que se impuseram sob o corpo de mulheres negras no decorrer da primeira metade do século XX imputaram a ele a beleza nacional, fazendo com que mulheres negras, mestiças, pardas e mulatas estivessem representadas em cada jovem negra eleita rainha ou miss, transformando a dura realidade discriminatória em momentos de alegria e reconhecimento.

A afirmação da identidade racial de mulheres negras se dava, pois, pela aceitação de suas características físicas em adequação ao que era veiculado pela publicidade e pela mídia como elementos constituintes da beleza em mulheres. Cremes, tratamento para cabelos crespos, maquiagens e o próprio bronzeamento podem ter sido utilizados por mulheres negras como meio de inserção de sua imagem aos certames que tratavam da beleza feminina. A beleza negra feminina, tanto como modelo de comportamento social como pela estética, se torna assim um retrato do reconhecimento racial da população negra no período de 1930 a 1945.

\section{Considerações finais}

O que se observou na sociedade brasileira entre 1930 e 1945 foi uma pretensão em se estabelecer um perfil imagético e estético que muito se diferenciava das condições em que se encontrava a população negra.

A luta antirracista por meio da constituição de um padrão de beleza que confrontasse o padrão vigente transformou a beleza negra feminina em um processo de construção e reconstrução de identidades por meio da estética, "com base em escolhas e contatos dos negros com um padrão estético que já está dado no campo das relações de poder, ou seja, o branco" (GOMES, 2008, p. 270). Dessa maneira, a construção sócio-histórica da beleza negra se organizou de maneira a atender às necessidades sociais dos negros no início do século XX, enfrentando e ao mesmo tempo adequando suas características ao branqueamento, lidando de maneira conflitante com a "boa aparência", tentando, por meio de reconstruções e ressignificações, alcançar seu ideal estético em meio ao modelo eurocêntrico. Convém, a partir dessa perspectiva, os concursos de beleza negra e as entrevistas com as vencedoras. Uma clara demonstração imagética de valorização das mulheres negras em meio à sociedade racista e sexista.

A partir de iniciativas com as da Frente Negra Brasileira e do Teatro Experimental do Negro, o que se observa é o enfrentamento da brancura através do reconhecimento étnico de suas características fenotípicas, alterando padrões, denunciando as mais diversas formas de discriminação racial e alijamento social no seio da democracia racial, trazendo à sociedade o que esta se negava a encarar: "no imaginário social, a mulher brasileira bela de 
corpo é aquela que apresenta o quadril e o bumbum avantajados e a cintura fina, algo típico das nossas raízes africanas" (GOMES, 2008, p. 293).

A mulher brasileira, então, guardou em sua significação os atributos corporais de mulheres negras e mulatas. O que podemos perceber como parte da composição desse perfil é um conjunto de características físicas que ilustraram os jornais da época imperial, os anúncios de escravizados fugitivos, como também ilustrou e construiu a imagem da mulata, com seus gostos, aromas e cores na literatura brasileira. Como nos diz Nina Rodrigues (apud GIACOMINI, 2007, p. 93, IO2), a representação da mulata era uma "representação clássica" e "exclusiva". Percebe-se, então, nessas associações negras do início do século XX, uma tentativa de aglutinar as exclusivas características da mulata, relacionadas principalmente à aparência, ao comportamento social das mulheres brancas - o que poderia construir o tipo ideal de mulher negra representante da população negra brasileira, daí a ênfase na instrução e no pudor junto com os cuidados com a aparência.

O que ocorreu com a população negra no constituir de sua corporeidade estética foi o que Nilma Lino Gomes (2008) ressaltou como uma adaptação das diferentes linguagens encontradas para a sobrevivência na diáspora: um envolvimento complexo entre os modelos brancos, os mestiços com as suas especificidades físicas e aqueles portadores dos caracteres negroides. Assim, a estética de mulheres negras foi construída a partir da dominação branca, mas não em conformidade com ela. As diferentes maneiras com as quais mulheres negras brasileiras podem fazer uso de seus cabelos e também de sua pele, por conta dos bronzeamentos, permitem que a corporeidade dessas mulheres seja desenhada, constituída ou apenas expressada de maneira a refletir toda a gama de proposições interculturais existentes na sociedade brasileira.

\section{Referências}

ALBERTO, P. L. A Mãe Preta entre sentimento, ciência e mito: intelectuais negros e as metáforas cambiantes de inclusão racial, I920-I980. In: GOMES, F.; DOMINGUES, P. (Org.). Políticas da raça: experiências e legados da abolição e da pós-emancipação no Brasil. São Paulo: Selo Negro Edições, 20I4. p. 377-40I.

BENTO, M. A. Branqueamento e branquitude no Brasil. Rio de Janeiro. Disponível em:

<https://www.ceert.org.br/programas/educacao/premio/premio4/textos/branqueamento _e_branquitude_no_brasil.pdf $>$. Acesso em: I2 out. 2015.

BOURDIEU, P. Questões de sociologia. Lisboa: Fim de Século, 2003.

BRAGA, A. História da beleza negra no Brasil: discursos, corpos e práticas. São Carlos: EdUFSCar, 2015. 
CORRÊA, M. Sobre a invenção da mulata. Cadernos Pagu, Campinas, n. 6/7, p. 35-50, jan. 2010. Disponível em: $<$ https://periodicos.sbu.unicamp.br/ojs/index.php/cadpagu/article/view/1860/198I >. Acesso em: 16 dez. 2017.

DAMASCENO, J. Corpo de quem? Espetáculo e ciência no século XIX. Revista Eletrônica de Jornalismo Científico, n. 92, out. 2007. Disponível em: $<$ http://www.comciencia.br/comciencia/handler.php? section=8\&edicao=29\&id=338> . Acesso em: 28 maio 2017.

DAMASCENO, C. Segredos da boa aparência: da "cor" à "boa aparência" no mundo do trabalho carioca (1930-1950). Seropédica: Edur, 2010.

DELEUZE, G. Nietzsche e a filosofia. Rio de Janeiro: Editora Rio, 1976.

DOMINGUES, P. A nova abolição. São Paulo: Selo Negro, 2008.

DOMINGUES, P. Frentenegrinas: notas de um capítulo da participação feminina na história da luta anti-racista no Brasil. Cadernos Pagu, n. 28, p. 345-374, jan./jul. 2007. Disponível em: $<$ http://www.scielo.br/scielo.php?pid=SoI04-83332007000IO00I5\&script=sci_arttext $>$. Acesso em: I4 ago. 2015.

FLORES, M. B. R. Tecnologia e estética do racismo: ciência e arte na política da beleza. Chapecó: Argos, 2007.

FOUCAULT, M. Microfísica do poder. 4. ed. Rio de Janeiro: Edições Graal, 1984.

GIACOMINI, S. M. A alma da festa: família, etnicidade e projetos num clube social da Zona Norte do Rio de Janeiro - o Renascença Clube. Belo Horizonte; Rio de Janeiro: Editora UFMG; IUPERJ, 2006.

GIACOMINI, S. M. Sexo e raça na construção da nação brasileira. Uma leitura das representações sobre a mulata. Interseções: Revista de Estudos Interdisciplinares, Rio de Janeiro, HP Comunicação Editora/UERJ, NAPE, ano 9, n. I, p. 89-IO5, 2007.

GOMES, N. L. Sem perder a raiz: cabelo e corpo como símbolos da identidade negra. 2. ed. Belo Horizonte: Autêntica, 2008.

LOPES, M. A. Beleza e ascensão social na imprensa negra paulista (I92O-I94O). Dissertação (Mestrado) - Pontifícia Universidade Católica de São Paulo, São Paulo, 2002.

MUNANGA, K. Rediscutindo a mestiçagem no Brasil: identidade nacional versus identidade negra. 3. ed. Belo Horizonte: Autêntica, 2008.

NASCIMENTO, E. L. O movimento social afro-brasileiro no século XX: um esboço sucinto. In: NASCIMENTO, E. L. (Org.). Cultura em movimento: matrizes africanas e ativismo negro no Brasil. São Paulo: Selo Negro, 2008. p. 93-I78. (Col. Sankofa: Matrizes Africanas da Cultura Brasileira 2). 
NEPOMUCENO, B. Mulheres negras: protagonismo ignorado. In: PINSKY, C. B.; PEDRO, J. M. Nova história das mulheres no Brasil. São Paulo: Contexto, 20I3. p. 382-409.

RAGO, M. Trabalho feminino e sexualidade. In: DEL PRIORE, M. (Org.). História das mulheres no Brasil. Io. ed. São Paulo: Contexto, 2013. p. 578-606.

SANT'ANNA, D. B. História da beleza no Brasil. São Paulo: Contexto, 2014.

SANTOS, R. A. Pau que nasce torto, nunca se endireita! E quem ébom, já nasce feito? Esterilização, saneamento e educação: uma leitura do eugenismo em Renato Kehl(1917-1937). Tese (Doutorado) - Departamento de História, Universidade Federal Fluminense, Niterói, 2008.

SCHWARCZ, L. M. O espetáculo das raças: cientistas, instituições e questão racial no Brasil I870-I930. São Paulo: Companhia das Letras, 1993.

SILVA, A.; GOELLNER, S. V. Sedentárias e coquettes à margem: corpos e feminilidades desviantes na obra de Renato Kehl. Revista Pensar a Prática, v. I, n. 3, p. 25I-259, set./dez. 2008. Disponível em: <http://www.revistas.ufg.br/index.php/fef/article/view/4865/497I $>$. Acesso em: 19 out. 2015.

SILVA, J. G. Nós também somos belas. A construção social do corpo e da beleza em mulheres negras. Dissertação (Mestrado) - Programa de Pós-graduação em Relações Étnico-raciais, Centro Federal de Educação Tecnológica Celso Suckow da Fonseca, Rio de Janeiro, 2015.

SIQUEIRA, M. B. Samba eidentidade nacional: das origens à Era Vargas. São Paulo: FEU, 2012. STEPAN, N. L. Eugenia no Brasil, I9I7-I94O. In: HOCHMAN, G.; ARMUS, D. (Orgs.). Cuidar, controlar, curar: ensaios históricos sobre saúde e doença na América Latina e Caribe. Rio de Janeiro: Editora Fiocruz, 2004.p. 33I-39I.

XAVIER, G. Leitoras: gênero, raça, imagem e discurso em O Menelick (1915-I9I6). Revista AfroÁsia, n. 46, p. I63-19I, 2012. Disponível em: $<$ http://www.scielo.br/pdf/afro/n46/ao5n46.pdf >. Acesso em: 3 jul. 2015.

XAVIER, G. Segredos de penteadeira: conversas transnacionais sobre raça, beleza e cidadania na imprensa negra pós-abolição do Brasil e dos EUA. Revista Estudos Históricos (Raçae História), Centro de Pesquisas e Documentação Contemporânea do Brasil da Fundação Getúlio Vargas, Rio de Janeiro, v. 26, n. 52, p. 429-450, jul./dez. 2013. 